\title{
In Memoriam - A Tribute to Raj Kumar Gupta
}

On September 25, 2012, Dr. Raj Kumar Gupta died in Wellington, New Zealand. He served a distinguished career in the medical profession spanning over 50 years and was a recognized international authority in cytopathology, where he contributed towards the increased understanding of this complex medical area. He was a Fellow of the College of American Pathologists (1971), Fellow of the International Academy of Cytology (1977), Diplomate of the International Board of Cytopathology (1980), Fellow of the Royal College of Physicians and Surgeons (Canada 1979), and Affiliate of the Royal College of Pathologists of Australia.

Born in India in 1932, he earned his MBBS at Agra University in 1957. He also completed his thesis for his MD at Vikram University, India, in 1960. Dr. Gupta served in the Medical College Hospital in Gwalior between 1957 and 1958 and then as Senior Lecturer in Pathology at MA Medical College, New Delhi, between 1960 and 1961. He emigrated to North America in 1962, where he trained in pathology at the Massachusetts General Hospital Harvard Medical School-affiliated training program at Worcestor Memorial Hospital and served as Senior Resident in Anatomic Pathology (1964). He completed his postgraduate study in cytopathology at the Postgraduate Institute of Cytology at Johns Hopkins University (1972).

From 1965 to 1979, Dr. Gupta served as Associate Professor of Pathology at the State University of New York School of Medicine and its affiliate University Hospitals in Buffalo, New York, and as Consultant Pathologist to

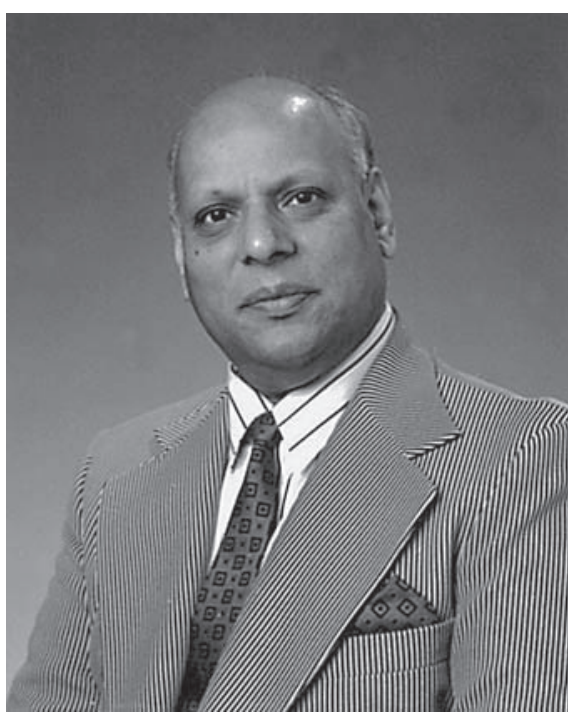

Raj K. Gupta, 1932-2012

the Niagara Regional Hospitals and affiliate laboratories from 1967 to 1979 (Canada). From 1979 to 1981, he served as Professor of Pathology at the National University of Singapore Faculty of Medicine and its affiliate University Hospitals. Dr. Gupta moved to Wellington, New Zealand, in 1981. There he served as Senior Consultant Cytopathologist and Head of the Cytology Unit to the Wellington Regional Hospital and School of Medicine, where he was consulted on literally thousands of cases until his retirement in December 2003. He continued to serve as Se-

\section{KARGER}

Fax +4161306 1234

E-Mail karger@karger.ch

www.karger.com
(C) 2012 S. Karger AG, Basel

0001-5547/13/0571-0115\$38.00/0

Accessible online at: www.karger.com/acy 
nior Consultant Cytopathologist in private practice until June 2009.

Dr. Gupta specialized in fine-needle aspiration cytology (FNAC), where he was particularly noted for his work. In 1983, he introduced the FNA procedure to New Zealand and spearheaded its use with the result that the procedure is now widely used in the New Zealand clinical domain. In the 1980s, his work at Wellington Hospital also contributed to the development of a pioneering procedure (at the time) called peritoneal cytology for diagnosing appendicitis which revolutionized the treatment of the condition, saving hospitals and patients money. This procedure improved the accuracy of diagnosis by as much as $95 \%$, also having implications for the diagnosis of abdominal cancer.

Dr. Gupta had an extensive publication record as an author of over 250 medical articles in peer-reviewed journals and published in the top high-ranked international journals in cytopathology, where he illuminated major aspects of FNAC inspired by clinical problems and rare findings.

His technical staff and medical residents in cytopathology remember him as a fatherly figure who mentored and delivered high-quality training to them, while always encouraging their professional development, and led a stimulating, encouraging, and productive environment. As a strong proponent of continuing medical education, Dr. Gupta regularly secured and organized visiting lectures for leading American cytopathology experts from the USA to visit Wellington and share their knowledge with the New Zealand medical community.

Dr. Gupta was a member of the editorial boards of Acta Cytologica (2008), Diagnostic Cytopathology (1995), and The Breast Journal (1995). He was a member of the International Committee of the Papanicolaou Society of Cytology (1994) and acted as an invited reviewer for the Journal of Experimental Biology and Medicine, American Review of Respiratory Diseases, Cytopathology, and Breast Cancer Research and Treatment.

Throughout his career in cytopathology, Dr. Gupta demonstrated a unique dedication and commitment to the field which was marked by insight, accomplishment, and the ability to share his insight with others, for which he remained very modest.

Dr. Gupta is survived by his two daughters, two sons, and six grandchildren.

Acta Cytologica is grateful to have had Dr. Gupta contribute over the years of his medical career to the journal in the field of cytology and be a member of its distinguished editorial board. 